\title{
Comunicación menor como forma de resistencia
}

\section{Artículo de reflexión}

\section{Elena Sánchez Velandia}

Escuela Translingüística de filosofía

elesanchezvelandia@gmail.com

Recibido el : 13/07/2020

Aceptado el : 16/10/2020

Cómo citar este artículo: Sánchez Velandia, E. (2021). Comunicación menor como forma de resistencia. Calle 14: revista de investigación en el campo del arte. 16(30), pp.344-359. https://doi.org/10.14483/21450706.18305

Este artículo recoge algunas de mis reflexiones elaboradas en el marco de la estancia postdoctoral que realicé en la Pontificia Universidad Católica de São Paulo durante el 2018, agradezco a Rogério da Costa y Lucia Leão por haberme acogido.

\section{(c) (1)}

https://creativecommons.org/licenses/by/4.0/deed.es 


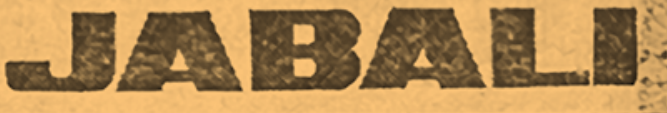

DALMiRo SAENZ entró con aire Jü dibujar en un cuaderno, con una de vencedor, el 30 de jullo pasa. fojpicera casi monstruosa, sus conodo, porkndo un dabal cazace en toda reunión social. Vicente Lopez. Lo reclb!6, ya pre- soal implica que sú capacidad de venida Sus a comunicación, de no-partic.pa. extrañadi ese di de sus tareas de . Cón, es tan grande en un "happendirectora de una galeria de arte kong como en una reunión social. Se acababa de dar el prlmer paso s = Aunque esto último depende, segucon creto para la realización del tzamente, del tipo de reunión, Egle "happening" que tendria por esce. Martin, actriz, bailarina, coreógrafa, narlo esa casa al dia sigulente, el título de Participacion total, concebido colectivamente (lo indican las noreglas del género) y reanzza. y Raúl Escarl, y el plístico Roberto Jacoby.

Como es llógico, cada uno de lo particlpantes de ese tipo de expoc táculo-juego-comunicacín hizo also por su cuenta, independientemente de los demis:, pero dejarndose lis var por reacciones espontaineas que, de o que hacía otra persona o grupo Los reallzadores manejaron los gutiles hilos invlsibles, en eferctclo de Ing" que cumplen por cuenta del tituto Di Tella.

El final "por toda la compañă" más los espectadores-comparsay, fue

cuente plato y el complementoni un excelente vino de su Neuciuén natal.

Es diffell, y ademís inuitil, juzgar in "happeníng" So'o se puede on tentar una aproximacín a la parti. cipación de cada uno, para tratar de establecer en qué meciida realmente participaron y, por lo mismo, skfe

Manuel Jifulica L álnez, por ejem. plo, el critico de arte cuya opinton pesa tanto en nuestro medlo, eskri. tor importante y espectador perma nente, escogió ubletos rincones pa sumio negro de candombe, anticipando un espectáculo que prepara. pociemos decir, por lo mismo, que recló die la gratuidad necesarla para que se justificara. Idéntico reproche se puede formular al plntor $y$ di. tor $y$ poeta Rodolfo Relman, quie. fes representaron fragmentos de $\mathrm{St}$ arquitecto y el emperador de Asiric, pieza del espanol Francisco Arrapi, todavia no estrenada mundialgrente. Aunque el caracter de csta flening". Marta Lynch aprovechó ?a noche para estructurar un relato, Trspirada por lo que estaba presen. jarea coherente para una cecritora tempoco se inscribe en la línea rie -ese tipo de espectáculo. Antonio

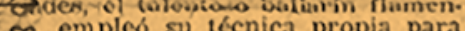
Dojuar música de los Rolling Stones. - beatles y algún candombe, ins. truido en el momento por Egle Mirtruido en el momento por Egle MirFernánciez de Rosa adoptaba el dis. raz de Adolfo Hitler para pasears? intre ios concurrentes, gritando Sr. denes en alemán apocrifo. De prono tuvo que partir velozmente, puits su hija Valentina estaba por ver la jyz. Ambos entraron en el juezo Con buena voluntad, y generaron que es, justamente, 10 propio del cando, y lo leyó más tarde: es una "happening". La noable ballar!na y coré́grafa moderna Graciela Martinez, actuaimente/ganada po: los espectaculos pop en los que cxhibe su real talento, tambien par tcipo en terminos vita.es. Danzo tin varios de los aststentes: Min. tin casalle - el actor uruguayo que protanizo la pelicula El carteris. las ballarinas Marilú Marini (nacida para el 'happening") y Chela Bsrtico Raúl Damonte Taborda, quien, a su vez, encarnó a su hijo-el cé lebre dibujante humorístico Cop! radicado en Paris- y como wit hacla una parodia de su padre que mismo, dibujada en publico y a la manera de Cop!. El sociólogo Juan José Sebrelli, también invitado, $r$ pudió formalmente el acto: "Este es un entretenimiento para «snobs"; Pero no se retiro sino hasta la co. cina $y$ reaparecio para apreclar el jabali, Oscar Nasot:a pronunclaba conferencias de 3 minutos de dura. clón, al ofdo de cada circunstante. operando una indivłdualización del "happening". convertido asi en un rumor. También Narta Minujín (au. tora de la frase: "El arte es thap. pening; la vida es ebsppenings: las más brillantes intervinientes: grababa los díĺlogos de los invlia. dos, a quienes fotografiaba y obs? quiaba al poco rato con una cop!a cie la foto, "para devolver a cada uno su imagen", según explícó.

Arturo Śez, dueño de casa, aśs artisticamente el jaball, configuran. do as la actividad mas vitalment celebrada del "happening". Otro3 asintentes, como la moxielada modefo Mercedes Robirosa, el persistente lizada pintora Lea Lubin - omlti. mos muchos nombres por razones de espacio- actuaron como par en las actividides de otros.

Un psicosanallsta prócer, PJeh Riviere, fue Invitado como obser clusiones no se han dado a conoc Escuchamos algunas frases sue. juicio. Marta Mímjin no devolvis imagen de nadie con sus fotos; Oscar Masutta desarrollaba una c y de que Graclela Martínez ha dado rienda suelta a una tenden hacia el predominio sobre los

Pensamos fuc este tipo de esp táculo - por darle un nombre no nos convence en absolutoplica muchas cosas complejub con la "espontaneidad" en la exp íón subconsciente y la simuita calidad de actor $y$ espectador arematuro extr conclusiones muy precisas. Es dente que, junto a quienes se ent gan y participan vitalmente Gades, Marila Marini, Fernández Rosa-, aparecen quienes en v dad son atraídos por la boga "sn del género ỳ su carácter de dist Egle Martip Jaime Jaimes, Reln Lynch, entie otros- Los resulta más visib!es se refieren a ese trionismo en estado naciente de hablabamos y a su funcion p cional entre gentes habituadas n bien a un clima intelectual. momentos, se genera una poesia tiva que revela a un ser hum: espontáneo y diversincado. Ese clas artístico-sociológico-psicoan ticas.

\section{Edmundo E. Eichelbaun}
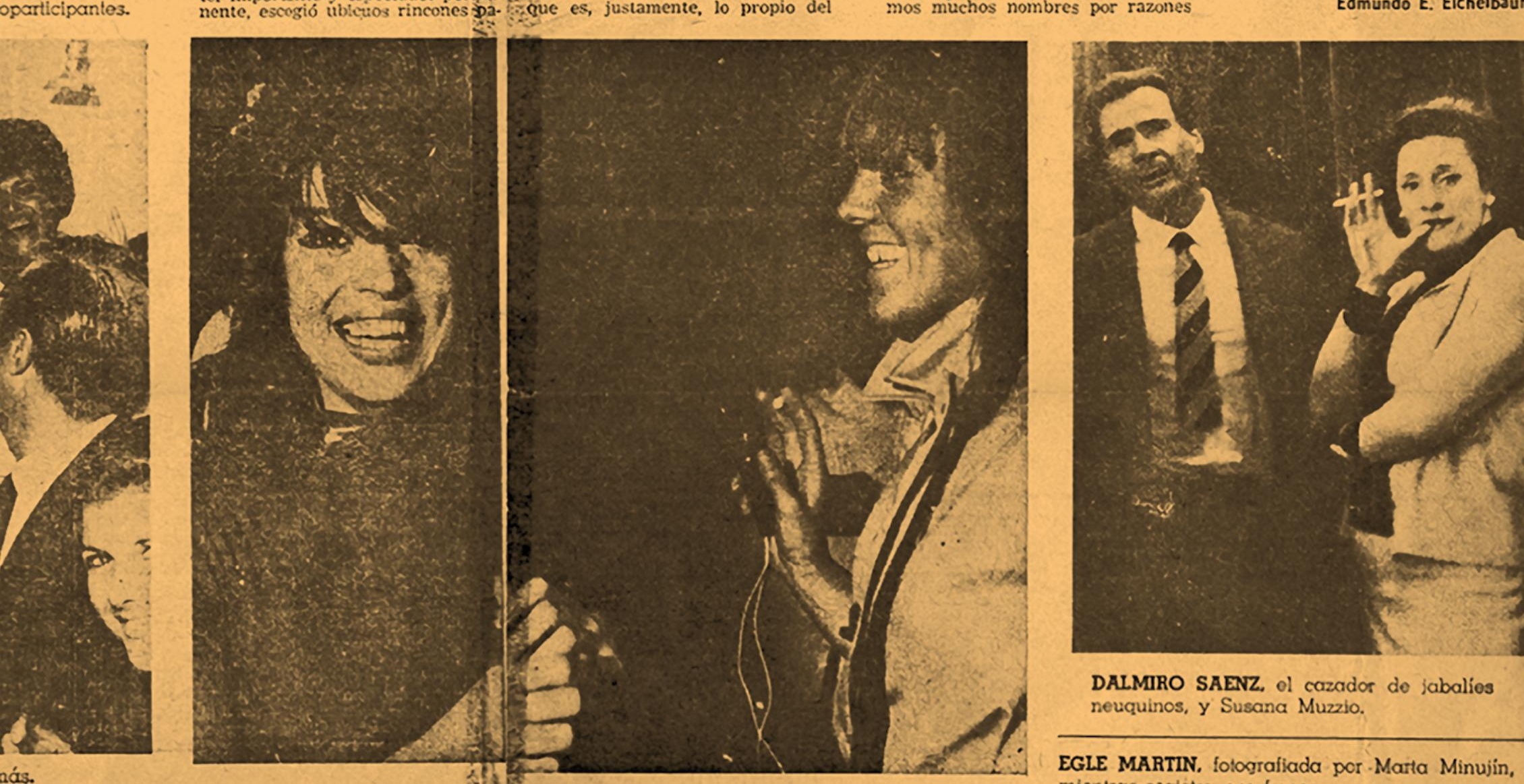

DALMIRO SAENZ, el cazador de jabalíes neuquinos, y Susana Muzzio.

EGLE MARTIN, folografiada por-Marta Minujin, 


\section{Resumen}

En este artículo construyo el concepto de "comunicación menor", confrontando el pensamiento de Gilles Deleuze (sobre todo en relación a la comunicación y a lo minoritario) con el arte conceptualista latinoamericano, apoyándome principalmente en el trabajo del artista y teórico Luis Camnitzer, que muestra, en particular, la relación entre el conceptualismo latinoamericano y la pedagogía de Paulo Freire. Observo entonces cómo opera dicha comunicación menor en tres propuestas artísticas, lo que me permite identificar tres estrategias posibles, para construir finalmente algunas reflexiones que desarrollan una comunicación menor hoy.
\end{abstract}

\title{
Palabras claves
}

Arte latinoamericano; Camnitzer; conceptualismo; control; Deleuze

\section{Minor communication as a form of resistance}

\section{Abstract}

In this article I build on the concept of "minor communication", confronting the thought of Gilles Deleuze (especially in relation to communication and the minority) with Latin American conceptualist art, relying mainly on the work of artist and theorist Luis Camnitzer who shows, in particular, the relationship between Latin American conceptualism and Paulo Freire's pedagogy. I then point to how this minor communication operates in three artistic proposals, which allows me to identify three possible strategies, to finally build some reflections that implement a minor communication today.

\section{Keywords}

Latin American art; Camnitzer; conceptualism; control; Deleuze

La communication mineure comme forme de résistance

\section{Résumé}

Dans cet article je construis sur le concept de « communication mineure », confrontant la pensée de Gilles Deleuze (notamment en relation avec la communication et la minorité) avec l'art conceptualiste latino-américain, en m'appuyant principalement sur le travail de l'artiste et théoricien Luis Camnitzer qui montre, en particulier, la relation entre le conceptualisme latino-américain et la pédagogie de Paulo Freire. Je pointe ensuite au fonctionnement de cette communication mineure en trois propositions artistiques, ce qui me permet d'identifier trois stratégies possibles, pour enfin construire quelques réflexions qui développent aujourd'hui une communication mineure.

\section{Mots clés}

Art latino-américain ; Camnitzer ; conceptualisme ; control ; Deleuze

\section{Resumo}

Neste artigo construo o conceito de "comunicação menor" confrontando o pensamento de Gilles Deleuze (sobretudo em relação a comunicação e ao minoritário) com a arte conceitualista latinoamericana (apoiando-me principalmente no trabalho do artista e teórico Luis Camnitzer que mostra, em particular, a relação entre o conceitualismo latino- americano e a pedagogia de Paulo Freire). Observo então, como opera essa comunicação menor em 3 propostas artísticas, o que 
me permite identificar 3 estratégias possíveis e concluo com algumas reflexões para desenvolver uma comunicação menor hoje.

\section{Palavras chave}

Arte latino-americana, Camnitzer; Conceitualismo; Controle; Deleuze

\section{Maillallachiska}

Parlitanakumi kai mailla kilkaskapi " uchulla parlata ialichidur" kawaspa iuia Gilles Deleuze suti ruraskata chasalla paita maki kuaskakuna sus runakuna Luis Camnitzer kawachiku paipa ruraita chasallata sug runa suti Paulo Freire. Kuaura kimsa kuna tandarispa Munanaku kanchasinama kawachinga paikuna ruraskata tukuikuna kawangapa.

\section{Rimangapa Ministidukuna}

Ruraikuna chasasuti llagtamanda; chasa suti runa; ñugpata llaki tiaskataapachidur; maikan urdinadur; chasa suti 


\section{Problemática general}

Concebir el arte en términos de información y comunicación fue una temática recurrente en el siglo XX, en particular en lo que se llamó arte conceptual/conceptualismo. La democratización de las computadoras, la aparición de Internet y la emergencia de las artes digitales parecen justificar y confirmar dicho devenir.

Al mismo tiempo, la "sociedad del control", como la llama Gilles Deleuze, estaría basada en la información. Incluso, en su conferencia sobre el acto de creación, Deluze identificaba la información y el control'1. Por consiguiente, si Deleuze tenía razón, esta reconceptualización del arte en términos de información ¿no le acarrearía el riesgo de ser subsumido por la lógica del control?

La paradoja sería grande si pensamos que, para algunos artistas este giro informativo se habría dado por motivos políticos. Según el teórico de arte Alex Alberro, la sustitución del "objeto mediador" por "las fuerzas incorpóreas de los medios de comunicación de masas" surgió en el contexto de "un movimiento social y político que luchaba contra las prácticas hegemónicas dominantes invocando sentimientos anti-coloniales y anti-imperialistas." (Alberro, 1999, pp. 140-141, traducción mía). El artista, teórico y curador Luis Camnitzer, por su parte, aproxima el conceptualismo a la pedagogía de la liberación de Freire e incluso a movimientos de guerrilla urbana como los Tupamaros (Camnitzer 2009).

En otras palabras, en América Latina ${ }^{2}$ la cuestión de la información en arte habría sido clave para desarrollar estrategias de resistencia política y de emancipación.

¿Se equivocaban entonces los conceptualistas latinoamericanos que pretendían usar la comunicación/ información para obtener objetivos políticos? ¿O por el contrario justamente esta transformación del arte en información implicaba una práctica crítica de la comunicación y de sus peligros?

1 "La información es exactamente el sistema del control." (Deleuze, 2012, p. 12)

2 Con esto no pretendo decir que solo en América Latina fue así ni que todo el arte latinoamericano que se preocupó por la cuestión de la comunicación/información o por la llamada superación del objeto artístico se pueden resumir en estos postulados.

\section{La sociedad de control}

Al volver a la famosa conferencia de Gilles Deleuze ¿Qué es el acto de creación? Parecería haber un equívoco en el modo de entender el concepto de sociedad de control hoy, pues se lo suele asociar a los conceptos de vigilancia y de privacy. Se piensa en un gran hermano que vigilaría todas nuestras comunicaciones, o en corporaciones que utilizarían nuestros datos incluso para manipularnos (como sucedió con Cambridge Analytica ${ }^{3}$ ) o en que el panóptico se habría fluidificado, por así decir, confundiéndose con el mismo cuerpo social: cada uno de nosotros sería al mismo tiempo el vigilante en la torre del panóptico y el vigilado en la celda.

Todas estas versiones de la sociedad de control parecen basarse en la idea de que la cuestión no es la comunicación en sí sino el modo perverso en que esta es usada por el Estado o por privados con poder económico o por nosotros mismos.

Sin embargo no fue en estos términos que Deleuze tematizó la sociedad de control por primera vez; él fue categórico: "en un primer sentido (...) la comunicación es la propagación y la transmisión de una información. ¿Y qué es una información? Una información es un conjunto de palabras de orden. Cuando se les informa, se les dice aquello que ustedes deben creer. (...) Lo que nos lleva a decir que la información es exactamente el sistema de control." (Deleuze, 2012, p. 12)

Es decir, la sociedad de control no se fundaría en un uso perverso de la comunicación sino en características propias de la comunicación en sí, que se potencian debido a la informatización que ha sufrido la vida en las últimas décadas.

Por demás, en ¿Qué es la filosofía? Gilles Deleuze y Felix Guattari nos dicen que la comunicación "solo se sirve de la potencia de las opiniones, para crear consenso y no concepto." (Deleuze \& Guattari, 1993, p. 12,) y la

3 En 2013 un profesor de Cambridge, Aleksandr Kogan, creó un test de personalidad para Facebook que aproximadamente 265000 usuarios completaron. Al hacerlo, concedieron acceso a información propia y de sus contactos (sin que estos lo supieran). En total Kogan obtuvo información de 50 millones de usuarios que vendió a la empresa Cambridge Analytica. Dicha empresa, que trabajó en la campaña presidencial de Donal Trump y la campaña pro-Brexit, entre otras, cruzó la información con datos de Facebook para "inferir perfiles psicológicos de cada usuario. Así, Cambridge Analytica logró saber cuál debía ser el contenido, tema y tono de un mensaje para cambiar la forma de pensar de los votantes de forma casi individualizada." (Redacción BBC Mundo, 2018) 
opinión es entendida en dicho texto como un modo convencional de la percepción y de la cognición que no permite ni el pensamiento ni la creación (dado que estos son singulares). En otras palabras, comunicar no es simplemente transmitir un mensaje de modo óptimo o eficaz, pues para que dicho mensaje sea entendido es necesario que emisores y receptores compartan una serie de creencias sobre lo real y una serie de formas de percibir el mundo y estas "opiniones" no son cuestionadas por la comunicación sino que, al contrario, son reafirmadas constantemente por ella.

Desde este punto de vista parecería entonces que la resistencia en la sociedad de control no debería pasar por la comunicación: no se trataría de salvaguardar la privacidad de nuestras comunicaciones (aunque no niego la importancia de hacerlo) o de corregir con contra-información la información sesgada producida por ciertos medios o regímenes. ${ }^{4} \mathrm{Al}$ contrario, se trataría más bien de contrarrestar la comunicación misma. Así, Deleuze habla de "vacuolas de no comunicación, interruptores para escapar al control" (Deleuze, 1995, p. 148). De este modo, en el mundo hiperconectado de hoy quisiera responder a la pregunta de cómo contrarrestar la comunicación, cómo construir estas vacuolas de no-comunicación, al interior de los medios de comunicación mismos. Para ello me inspiro en algunas ideas de Camnitzer, sobre el así llamado conceptualismo latinoamericano, que al confrontarlas con la teoría de Deleuze sobre el control y la comunicación me permiten construir el concepto de "comunicación menor".

\section{Hacia una "comunicación menor"}

De acuerdo con Camnitzer, el concepto de "literatura menor" sería útil para entender el conceptualismo latinoamericano.

Según Deleuze y Guattari "Una literatura menor no es la literatura de un idioma menor, sino la literatura que una minoría hace dentro de una lengua mayor." (Deleuze \&

\footnotetext{
$4 \quad$ A este respecto Deleuze afirma: "En tiempos de Hitler, los judíos que llegaban de Alemania y que eran los primeros a contarnos que había campos de concentración hacían contra-información. Lo que hay que constatar es que la contra-información no ha sido nunca suficiente. Ninguna contra-información le dio problemas a Hitler. Salvo en un caso. [...] La única respuesta sería que la contra-información no se vuelve verdaderamente eficaz sino cuando es $-y$ lo es por naturaleza- o se transforma en acto de resistencia. La contra-información no es efectiva sino cuando se transforma en acto de resistencia." (Deleuze, 2012, p. 14, traducción ligeramente modificada).
}

Guattari, 1978, p. 28). Dicho de otro modo, una literatura menor sería el modo en el que una minoría ${ }^{5}$ aprehende, atraviesa, transforma, desconcierta una legua mayor. Este concepto puede extenderse obviamente al arte en general, así, un arte menor sería el que una minoría produciría al interior de un "lenguaje" artístico mayor (un "lenguaje" artístico hegemónico), como sería el caso de una parte del conceptualismo latinoamericano que trabaja y transforma los "lenguajes" del arte contemporáneo a partir de las complejas realidades socio-políticas latinoamericanas. ${ }^{6}$

Dada la importancia de la comunicación en el desarrollo del conceptualismo latinoamericano (como lo vimos con Alberro y como sucede con artistas conceptualistas como Camnitzer, Roberto Jacoby o Cildo Meireles) es posible preguntarse si, además de un arte menor, el conceptualismo podría ser una especie de "comunicación menor" (o un "uso menor" de la comunicación, ver nota 6). Esta "comunicación menor" no sería comunicación, en el sentido de la transmisión de información, sino un modo de cortocircuitar la lógica de la comunicación que según Deleuze se funda en la opinión. Por ello, más que en la transmisión de informaciones la "comunicación menor" consistiría en acciones (o incluso en la transmisión de estas) realizadas en los medios o sobre los medios o en paralelo a estos.

5 Deleuze y Guattari definen la minoría así: "Minoría y mayoría no sólo se oponen de forma cuantitativa. Mayoría implica una constante, de expresión o de contenido, como un patrón de medida con relación al cual se evalúa. Supongamos que la constante o el patrón sea Hombre-blanco-macho-adulto-urbano-hablando una lengua standard-europeo-heterosexual cualquiera (el Ulises de Joyce o de Ezra Pound). Es evidente que 'el hombre' tiene la mayoría, incluso si es menos numeroso que los mosquitos, los niños, las mujeres, los negros, los campesinos, los homosexuales..., etc. (...) La mayoría supone un estado de poder y de dominación, y no a la inversa. Supone el patrón de medida y no a la inversa." (Deleuze \& Guattari, 2002, p. 107, traducción ligeramente modificada)

6 Según Anne Sauvagnargues "Lo que Georges Canguilhem escribe sobre lo viviente, a saber, que este 'gira en torno a su norma', Deleuze lo aplica a la teoría de la cultura. No se trata tanto de recusar las normas cuanto de modificar su estatus (...) la norma no está dada como un ideal que trasciende lo vivo, sino como una variación inmanente que cada ser vivo singular transforma. No existe una norma dada de una vez por todas para todo lo viviente, sino que cada ser vivo, en su singularidad, hace salir la norma de sus límites." (Sauvagnargues, 2002, p. 126, traducción mía) Este modo de relacionarse de lo vivo con la norma, inspira lo que Deleuze llama un "uso menor" de la norma: así, si una producción cultural "gira en torno a su norma", es decir que no la entiende como un ideal, que transciende a las formas culturales, sino como una variación inmanente que cada producción cultural re-actualiza, está desplegando un "uso menor" de la norma. 


\section{La comunicación en el arte conceptualista latinoamericano}

Como lo muestra Camnitzer no solo fueron teóricos de la información como Claude Shannon ${ }^{7}$ los que inspiraron la introducción de la cuestión de la comunicación en el conceptualismo latinoamericano, sino que quizás tuvo mayor relevancia Paulo Freire. El pedagogo brasileño desarrolla en su obra un modelo de la comunicación que no tiene nada que ver con el modelo lineal desarrollado por Shannon y que es una de las bases de su pedagogía. Para Freire la comunicación no consiste en la transmisión de un mensaje de un emisor a un receptor sino en un encuentro entre sujetos distintos del que surge la significación: "La educación es comunicación, es diálogo, en la medida en que no es la transferencia del saber sino un encuentro de sujetos interlocutores, que buscan la significación de los significados." (Freire, 1973, p. 77) Freire formula esta concepción en un texto titulado "Extensión o Comunicación" donde discute del modo en que los agrónomos se dirigían a los campesinos en Chile. La comunicación en dicho texto se opone a lo que él llama "extensión", que sería esa transmisión unidireccional del saber del experto al campesino.

Resulta curioso que Freire haya elegido la palabra comunicación para lo que en realidad indica una puesta en paréntesis de la comunicación: el experto deja de ser el emisor privilegiado y ahora también debe callar y escuchar. Pero no se trata simplemente de reemplazar la comunicación unidireccional ${ }^{8}$, clásicamente practi-

7 Shannon es considerado el fundador de la teoría de la información gracias a su texto "Una teoría matemática de la comunicación". 8 En "El comunicador popular", Mario Kaplún define la comunicación unidireccional como aquella que "fluye en una sola dirección, en una única vía: del emisor al receptor." (Kaplún, 1985, p. 25) Para Kaplún este tipo de comunicación es una comunicación "bancaria" (en analogía a la educación bancaria que Freire critica) en la que "El emisor es el educador hablando frente a un educando que debe escucharlo pasivamente. 0 es el comunicador que 'sabe' emitiendo su mensaje (su artículo periodístico, su programa de radio, etc.) desde su propia visión, con sus propios contenidos, a un lector (u oyente o espectador) que 'no sabe' y al que no se le reconoce otro papel que el de receptor de la información." (Kaplún, 1985, p. 24) En este sentido, la comunicación desarrollada por los medios masivos suele ser unidireccional. Kaplún analiza también el modelo de comunicación "basado en los efectos" cuyo objetivo es moldear conductas, y anota que, aunque en este modelo haya retroalimentación, la comunicación no es propiamente bidireccional pues la retroalimentación (o feedback) dada por el receptor "es tan sólo la comprobación o confirmación del efecto previsto es decir, la 'reacción del sujeto' ante la 'propuesta' o 'intento de comunicación'. Ella puede ser positiva si el individuo acata la propuesta o negativa si la rechaza. En este último caso, le sirve al emisor como instrumento de verificación y control". (Kaplun, 1985, p. cada por el experto, por una comunicación bidireccional donde tanto el agrónomo como el campesino son emisores y receptores que intercambian información. Buscar la "significación de los significados" implica ir más allá, deconstruyendo eso que Deleuze llama "opinión", para construir una nueva imagen de lo real partiendo del mundo del "oprimido" (expresión que Freire usaría después). Lo que Freire llama comunicación es más bien un uso menor de la comunicación en el que experto y campesino parten de un punto de vista minoritario (la realidad del campesino) para re-fundar la comunicación. ${ }^{9}$

Camnitzer transpone la formula freiriana al campo artístico: "El arte es comunicación puesta en marcha por artistas y espectadores en búsqueda del sentido de las significaciones." (Camnitzer, 2009, p.147) Según esto, el conceptualismo (como lo concibe Camnitzer) sería una forma de desarrollar la "comunicación menor",

41) Finalmente Kaplún toma la noción de EMIREC (mezcla de emisor/ receptor) acuñado por Jean Cloutier (1973) en al que todos los participantes de la comunicación son emisores y receptores al mismo tiempo y en sentido pleno (no como en el caso de la comunicación conductista). En este caso la comunicación sería verdaderamente bidireccional. Mi posición es que la teoría de la comunicación de Deleuze permite comprender que esta bidireccionalidad no es suficiente para resistir al control pues no cuestiona el nivel de lo que Deleuze llama "opinión" que está implicado en la comunicación de modo irreflexivo. Además de las nociones de comunicación unidireccional y bidireccional existe la de "comunicación multidireccional" muchas veces asociada a las redes de comunicación digitales, como internet, aunque puede extenderse a redes de comunicación de otro tipo. En el contexto de la comunicación popular de Kaplún, ligada a la pedagogía, Ascención Palomares (2015) nos dice que se trata de una comunicación en la que todos son emisores y receptores activos, promoviendo la participación y expresión libres y en la que todos los "EMIRECS" tienen el mismo status y rango. Como veremos, una propuesta como la hecha por Cildo Meireles en "Inserciones en circuitos ideológicos" transforma la comunicación unidireccional desplegada por dichos circuitos en una comunicación multidireccional en la que los ciudadanos pasan de ser simples receptores de la ideología del circuito a ser EMIRECS conectados entre sí a través del mismo circuito.

9 Otra opción para resolver esta "paradoja" que podemos observar en Freire (usar el término "comunicación para denotar algo que implica una ruptura con la eficacia comunicativa) es la que nos ofrece el mismo Kaplún: “Comunicación deriva de la raíz latina COMMUNIS: poner en común algo con otro. Es la misma raíz de comunidad, de comunión; expresa algo que se comparte: que se tiene o se vive en común."

(1985 p. 64) Así, Freire y Kaplún estarían recuperando este sentido "latino" de la comunicación. Sin embargo no es claro que al poner en común algo con otro, al compartir, se superen las "opiniones" de las que nos habla Deleuze. De hecho la comunicación se basa en que estas "opiniones" presupuestas ya han sido puestas en común y son compartidas por emisores y receptores. Otra cosa sucede en cambio cuando se pone en común un acto de creación, como lo sugiere Deleuze, que implica precisamente cuestionar dichas "opiniones". 
que pudimos identificar en la propuesta de Freire, en el campo del arte.

A continuación, vamos a observar cómo se despliega la comunicación menor en tres propuestas artísticas. No se trata entonces de un análisis general de estas propuestas (sobre las dos primeras se ha escrito bastante) sino de indagar aspectos de la comunicación menor gracias a ellas.

1. El Happening que nunca tuvo lugar

En octubre de 1966, los artistas argentinos Eduardo Costa, Raúl Escari y Roberto Jacoby llevaron a cabo una obra que tomó varios nombres: "Participación total", "Primera obra de arte de los medios", "El Happening que nunca tuvo lugar", "Happening para un Jabalí difunto". Se trató de la realización de un proyecto que habían anunciado en un manifiesto ("Un arte de los medios") publicado unos meses antes:
“El arte actual (fundamentalmente el Pop) tomaba, a veces, para su constitución, elementos, técnicas, de la comunicación de masas, desconectándolos de su contexto natural. [...] A diferencia del Pop, nosotros pretendemos constituir la obra en el interior de dichos medios. De este modo, nos proponemos entregar a la prensa el informe escrito y fotográfico de un happening quo no ha ocurrido. Este falso informe incluirá los nombres de los participantes, una indicación del lugar y momento en que se realizó y una descripción del espectáculo que se supone que ha ocurrido, con fotos tomadas a los supuestos participantes en otras circunstancias. Así, en el modo de transmitir la información, en el modo de 'realizar' el acontecimiento inexistente, en las diferencias que surjan entre las diversas versiones que del mismo suceso haga cada emisor, aparecerá, el sentido de la obra. Una obra que comienza a existir en el momento mismo

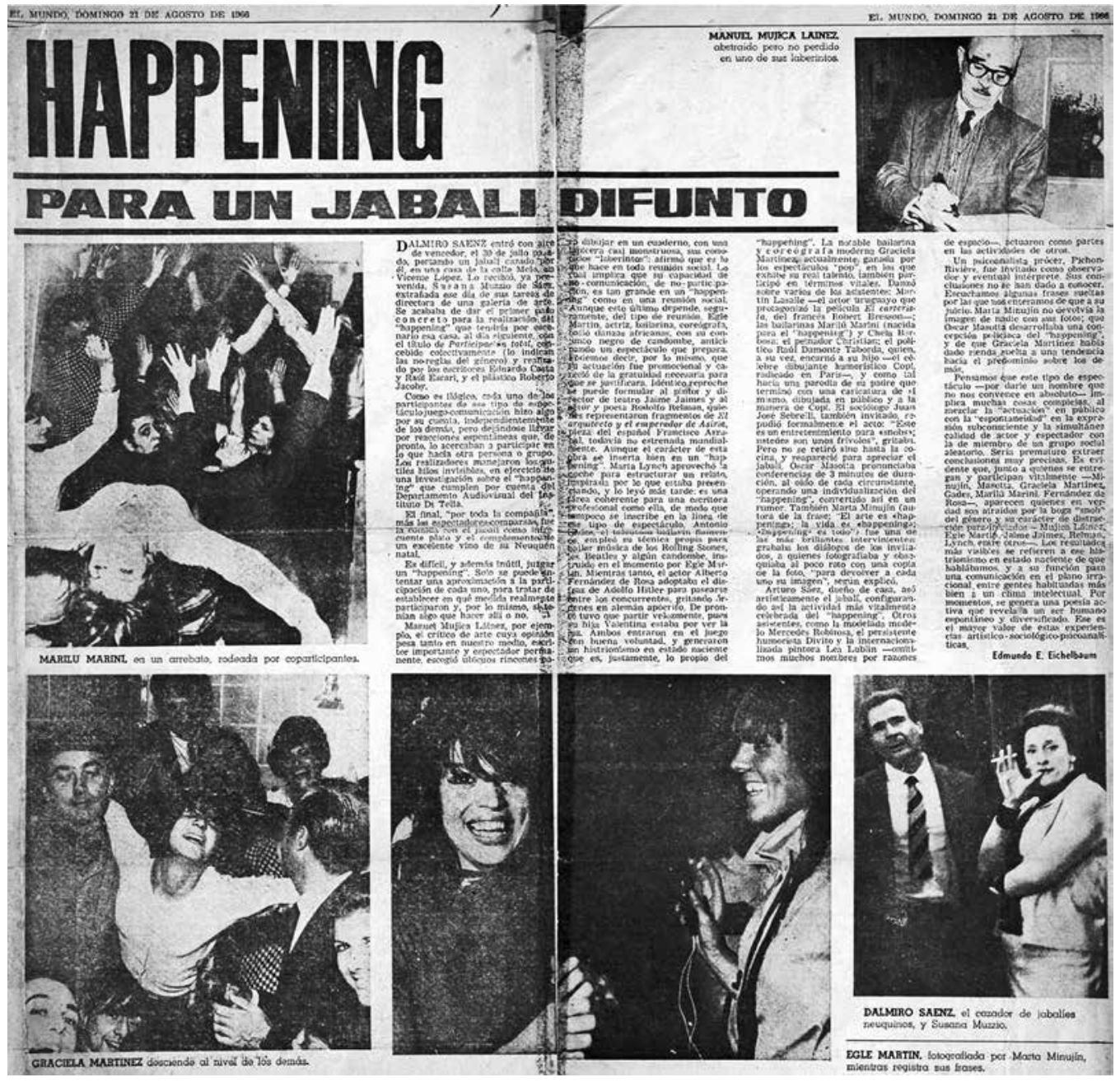

Imagen 1. Eichelbaum, Eduardo E. (21 de agosto de 1966). Happening para un jabalí difunto, El Mundo, Buenos Aires. Recuperado de: https://icaadocs. $\mathrm{mfah} . \circ \mathrm{rg} / \mathrm{s} / \mathrm{en} / \mathrm{item} / 750866 \# ? \mathrm{c}=8 \mathrm{rm}=8 \mathrm{rs}=8 \mathrm{ccv}=8 \mathrm{cxywh}=-651 \%$ 2C-160\%2C6551\%2C3666 
en que la conciencia del espectador la constituye como ya concluida." (Jacoby, 2011, p. 49)

La última oración también podría aplicarse a una obra que Jacoby había propuesto en mayo de 1966: “[...] una exposición que fuera solo el relato de una exposición." (Jacoby, 2011, Jacoby, 2011, p. 63) Sin embargo, presentado por ejemplo en una galería, el "Happening que no tuvo lugar" se referiría principalmente a una tesis fundamental en el arte contemporáneo: la idea de que la obra no existiría sino como lectura pues su manifestación física no sería su configuración final que se lleva a cabo solo en el lector o en el espectador. Más específicamente, el conceptualismo implica que el lugar real de actualización de la obra se ha desplazado desde un objeto físico a la mente del espectador.

Pero la especificidad del "Happening que nunca tuvo lugar" no se encuentra en este desplazamiento de la participación física a la participación mental del público (aunque lo presupone) sino en un plano que se suma al precedente y que radica en la relación entre los medios de comunicación y la realidad. Los medios de comunicación no son simplemente espejos (así sean deformantes) que reproducen la realidad: interactúan con ella, la transforman, la crean.

En su texto "Contra el Happenning" (publicado en 1967), Jacoby declara esta especificidad del "Happening que no tuvo lugar" y nos dice cómo fue ocultado por otras explicaciones de la obra:

“Para su realización fue necesario obtener la adhesión de los supuestos participantes, y de los periodistas. A cada uno le aclarábamos nuestros objetivos, que cada uno quería oír. Si alguien pensaba que todo no era más que una gran broma, lo convencimos de que efectivamente lo era (técnica de las relaciones públicas). Estas explicaciones ad hoc se confundían con las verdaderas intenciones que teníamos al crear la obra: más tarde contribuyeron a complicar su inteligibilidad. Una de esas explicaciones consistía en reducir la intención de la obra a demostrar que la prensa engaña o deforma. Este fenómeno que es obvio y de sentido común es, en realidad solo tocado tangencialmente. Lo que había en nuestro trabajo de fundamental es algo más complicado; un juego con la realidad de las cosas y la irrealidad de la información, con la realidad de la información y la irrealidad de las cosas, con la materialización por obra de los medios de información masivos de hechos imaginarios, el de un imaginario construido sobre un imaginario; el juego de construir una imagen mítica y el trabajo de buscar la adhesión imaginante de la audiencia para tirarla abajo y dejarle solo el espectáculo de su conciencia engañada." (Jacoby, 2011, p. 71)

La comunicación que despliega la prensa se basa en la idea de que la realidad está "ahí afuera"; la información se limitaría a representar la realidad, en el mejor de los casos de modo objetivo, en el peor de modo sesgado o parcializado. El "Happening que nunca tuvo lugar" rompe con esta "opinión", quebrando la frontera entre los hechos y sus presuntas representaciones llevando a cabo la acción de construir a través de los medios, de no dejarles la prerrogativa de construir la realidad y por lo tanto de definirla. Así, Jacoby nos habla de un juego donde lo real oscila: entre la información y los hechos no logramos decidir cuál es el epifenómeno y cuál es la realidad.

El "Happening que nunca tuvo lugar" nos sugiere una estrategia posible de comunicación menor: aquella de detonar las "opiniones" que fundan la comunicación en sí, los presupuestos que garantizan el funcionamiento mismo de la comunicación.

\section{Inserciones}

En su trabajo Inserções em Circuitos Ideológicos, Cildo Meireles imprimió mensajes en botellas vacías de CocaCola [projeto Coca-Cola] y en billetes de cruzeiros [projeto Cedula], alentando a la gente a agregar sus propios comentarios. Como escribe Camnizer:

“Cildo Meireles se apropió de productos comerciales y de dinero, alteró sus mensajes, y los reinsertó en sus circuitos normales de circulación. Su intención fue utilizar para sus propios fines los mismos procesos de consumo que llevaban a la gente a alejarse de la posibilidad de comprensión de la realidad. Fue una forma de détournement situacionista." (Camnitzer, 2009, pp. 243-244)

En su comentario, Camnitzer presupone un elemento muy importante: nos dice que Meireles "alteró" los mensajes que ya están presentes en las botellas de Coca-Cola y en los billetes. Esto significa que no sería Meireles quien convertiría esos objetos en vehículos de mensajes, sino que ya son parte de sistemas de comunicación que vehiculan sus propios mensajes. De ahí 


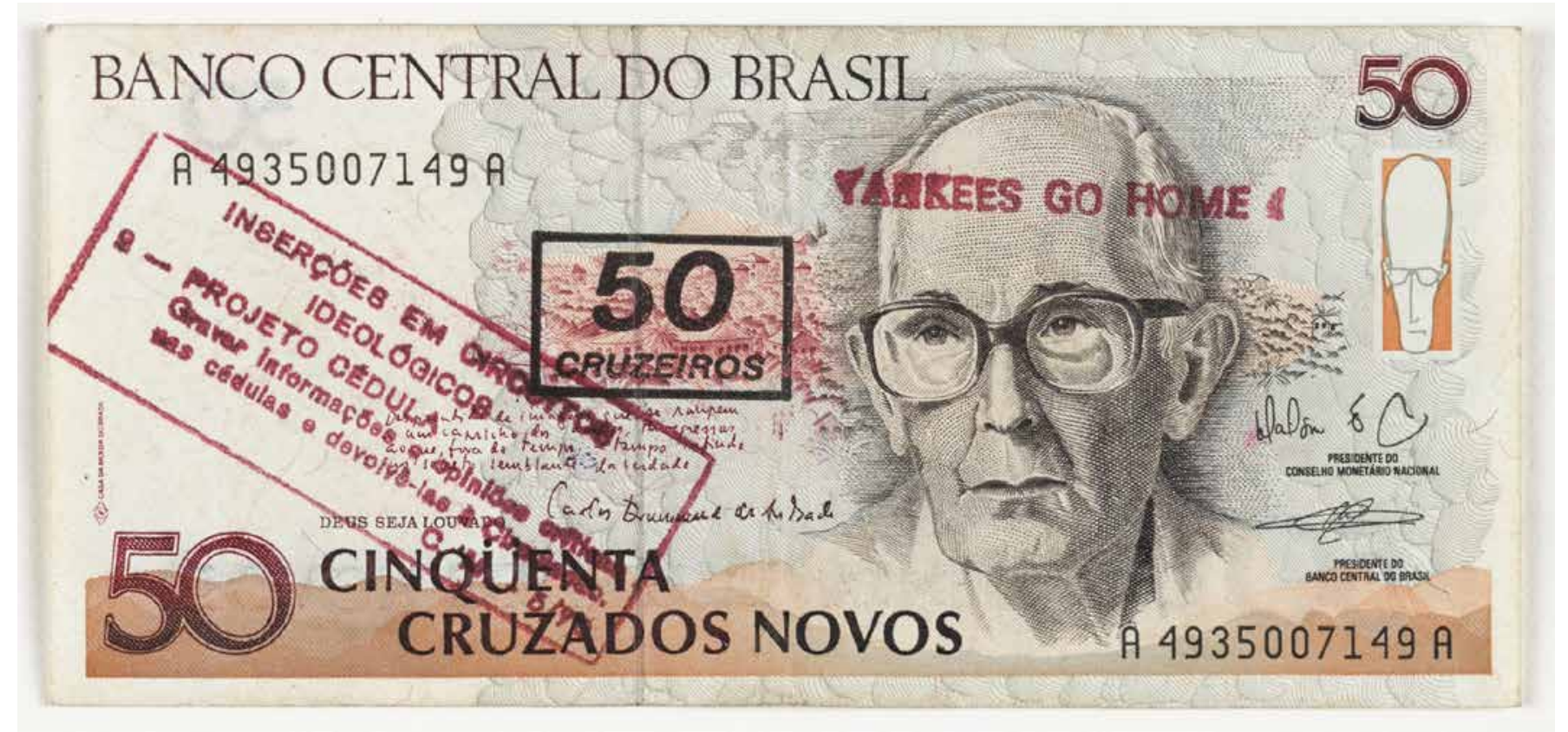

Imagen 2. Cildo Meireles. Inserções em Circuitos Ideológicos 2: Projeto Cedula, 1970. Sello de goma, impreso en ambos lados de un billete de cincuenta cruzados novos brasileños. Recuperado de: https://www.moma.org/collection/works/62048

el título de la obra: Meireles "inserta" sus mensajes en "circuitos ideológicos"; los circuitos de circulación de mercancías, o de dinero, no son solo circuitos de distribución sino también de comunicación, transmitiendo "propaganda ideológica":

"Desde mi punto de vista", dice Meireles, "lo importante en el proyecto fue la introducción del concepto de 'circuito', aislándolo y fijándolo. Es este concepto el que determina la carga dialéctica del trabajo, una vez que parasitaría cualquier esfuerzo contenido en la esencia misma del proceso (medios de comunicación). Es decir, el contenedor vehicula siempre una ideología. La idea inicial fue, por lo tanto, la constatación del 'circuito' (natural), que existe y sobre el cual es posible hacer un trabajo real. De hecho, la inserción en este circuito siempre tendría el carácter de contrainformación. Se capitalizaría la sofisticación del medio a favor de la ampliación del acceso equitativo a la comunicación de masa, es decir, a favor de una neutralización de la propaganda ideológica original (de la industria o del estado) que siempre es anestésica." ${ }^{10}$ (Brito \& Macieira de Sousa, 1981, p.26, traducción mía)

10 "Do meu ponto de vista, o importante no projeto foi a introdução do conceito de 'circuito', isolando-o e fixando-o. E esse conceito que determina a carga dialética do trabalho, uma vez que parasitaria todo e qualquer esforço contido na essência mesma do processo (media). Quer dizer, a embalagem veicula sempre uma ideologia. Então, a idéia inicial era a constatação de 'circuito' (natural), que existe e sobre o qual é possível fazer um trabalho real.
Aunque el mismo Meireles habla de contrainformación, las Inserções... no se reducen a la contrainformación en el sentido de que Meireles se hubiese limitado a producir y difundir (a través de los canales tradicionales o no) mensajes que contradigan la Información hegemónica. Por ejemplo, no publica un artículo en la prensa que explique que los circuitos de circulación de mercancías también son medios de comunicación; en cambio, realiza una acción que muestra que estos circuitos son medios y que podemos parasitarlos con mensajes que no tienen nada que ver con ellos (la acción quizás se facilita precisamente porque estos circuitos no se presentan explícitamente como medios de comunicación). Además, los mensajes que Meireles difunde en botellas y billetes no son información que contradiga la información emitida por la dictadura o autorizada por ella. El mensaje "Yankees go home!" solo nos informa que quien lo escribió es muy probablemente un antiimperialista; no nos dice, por ejemplo, nada sobre la situación geopolítica que lo justificaría. El mensaje que explica cómo convertir una botella de Coca-Cola en un cóctel Molotov no contiene otra información más que eso (es decir, cómo convertir una botella de Coca-Cola en un cóctel Molotov, lo que no se puede calificar de contra-información). El

Na verdade, o caráter da 'inserção' nesse circuito seria sempre o de contra-informação.

Capitalizaria a sofisticação do meio em proveito de uma ampliação da igualdade de acesso à comunicação de massa, vale dizer, em proveito de uma neutralização da propaganda ideológica original (da indústria ou do Estado), que é sempre anestesiante." 
mensaje "¿Quién mató a Herzog?" no contiene información más allá del hecho de que su autor duda de la información emitida por la dictadura (según la versión oficial del gobierno, Herzog se habría suicidado). Finalmente, el mensaje "Escriba informaciones y opiniones críticas en los boletos y vuelva a ponerlos en circulación", más que información, es una invitación.

La contra-información de la que habla Meireles no está, por lo tanto, en los mensajes individuales que inserta en los circuitos, sino en la acción de inserción como tal. Es la inserción como tal la que nos indica que el circuito es al mismo tiempo un medio. En este sentido lo que Meireles hace parece verificar lo que dice Deleuze: “La contra-información no es efectiva sino cuando se transforma en acto de resistencia." (Deleuze, 2012, p. 14)

Por otro lado, las inserciones transforman las características mediáticas de los "circuitos ideológicos": como medios, los circuitos de mercancías y de dinero transmiten su "propaganda ideológica" del emisor (el estado o la fábrica) al receptor (los ciudadanos/consumidores) sin prever retroalimentación por parte de este último; en este sentido son unidireccionales. Al invitar a los ciudadanos a apropiarse de los "circuitos ideológicos" y convertirse en emisores (o EMIRECS como los llama Jean Cloutier; ver nota 8), Meireles convierte en multidireccionales dichos circuitos, los descentraliza:

“Las Inserções en circuitos ideológicos nacieron de la necesidad de crear un sistema de circulación, de intercambio de información, que no dependiese de ningún tipo de control centralizado. Una lengua. Un sistema que, en su esencia, se opusiera al de la prensa, la radio o la televisión, ejemplos típicos de medios de comunicación que alcanzan de hecho un público inmenso pero en cuyo sistema de circulación está siempre presente un determinado control y una determinada canalización de la inserción. O sea, en estos medios, la 'inserción' es ejercida por una elite que tiene acceso a los niveles en los que se desarrolla el sistema: sofisticación tecnológica vinculada a grandes cantidades de dinero y / o poder."11 (Brito \& Macieira de Sousa, 1981, p.26, traducción mía)

11 “[...] as Inserções em circuitos ideológicos nasceram da necessidade de se criar um sistema de circulação, de troca de informações, que não dependesse de nenhum tipo de controle centralizado. Uma língua. Um sistema que, na essência, se opusesse ao da imprensa, do rádio, da televisão, exemplos típicos de media que atingem de fato um público imenso, mas em cujo sistema de circulação está sempre presente um determinado controle e um determinado
De esta manera, Meireles parasitó unos medios de comunicación (los circuitos de distribución de mercancías y de dinero) para oponerse a otros (los medios de comunicación de masa). Llamaré a este tipo de estrategia de comunicación menor una estrategia de parasitaje.

\section{Museo de la Calle}

En los años 90 del siglo pasado, había en el centro de Bogotá un área llamada "La calle del Cartucho" (o simplemente "El Cartucho") que muchos bogotanos preferían evitar. Este lugar que se salía de la gramática urbana, del orden que constituye la ontología de la ciudad (por ejemplo, Angela María Robledo y Patricia Rodríguez [2008], lo llaman la "no-ciudad") compartía el mismo espacio que el palacio presidencial, el Congreso de la República, los ministerios, la alcaldía, importantes universidades, museos, bibliotecas, el turístico barrio colonial, importantes instituciones financieras y bancarias...

La alcaldía de Bogotá, cuyas oficinas principales se encuentran a unos 500 metros de lo que era El Cartucho, había encontrado la solución a los problemas sociales que planteaba: demolerlo. En su lugar se construiría un parque, "Parque del Tercer Milenio", de una dimensión de aproximadamente 20 hectáreas: para ello fue necesario comprar y derribar más de 600 edificios, muchos de los cuales pertenecían al patrimonio histórico de la ciudad, y evacuar más de 4000 habitantes de la zona con programas de reintegración social para aproximadamente 1500 de ellos. La política estética del alcalde, que buscaba hacer coincidir la apariencia visual del centro con su función simbólica. y, por lo tanto, restaurar las jerarquías espaciales tradicionales (centro-periferia), se basaba en una concepción del espacio público como un lugar neutro, libre de referencias corporales e históricas concretas. Por lo tanto, ciertos cuerpos humanos se vuelven accesorios o incluso indeseables, capaces de desfigurar el espacio, hacerlo menos atractivo o incluso repulsivo ... se olvida que estos cuerpos humanos, al habitar, transformar, alimentarse y alimentar, son condición de posibilidad del mismo espacio urbano.

afunilamento da inserção. Quer dizer, neles a 'inserção' é exercida por uma elite que tem acesso aos níveis em que o sistema se desenvolve: sofisticação tecnológica envolvendo alta soma de dinheiro e/ou poder." 


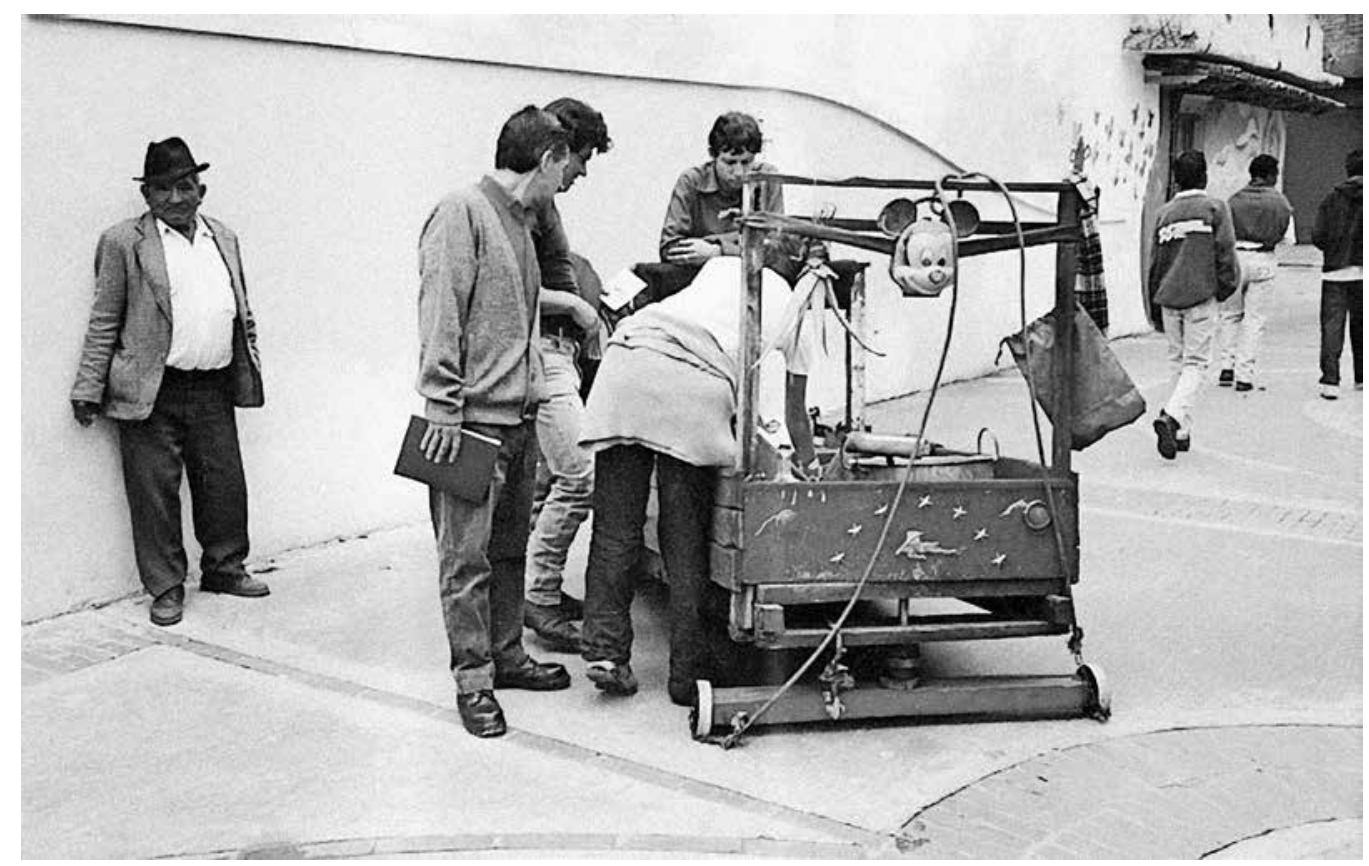

Imagen 3. Colectivo PTVC/Cambalache, Museo de la Calle, 1998-2002 proyecto artístico en el espacio público. Recuperado de: http://intercambiodearchivos.blogspot.com/2013/11/valor-es-dar-cuando-esnecesario.html

La ciudad se proyectaba así hacia el futuro ("el tercer milenio") gracias a la supresión de un pasado oscuro, doloroso y percibido como bárbaro.

Los participantes de un seminario dirigido por el artista español Federico Guzmán en la Universidad de los Andes (en 1998) quisieron responder a esta política estética colonial con una acción artística crítica.

En ese momento, Guzmán estaba interesado en aquellos dispositivos conocidos como "cápsulas de tiempo" (un contenedor en el que se depositan mensajes y objetos del presente y que permanece cerrado durante un cierto intervalo de tiempo para descubrir su contenido en el futuro). La cápsula de tiempo puede verse como una especie de archivo o museo elemental y permite activar, en la comunidad donde se propone, procesos de reflexión y negociación de la identidad de sus miembros, de las representaciones que la gobiernan, de las jerarquías ontológicas que pueden establecerse entre estas interpretaciones y de la forma en que esta identidad se imagina a partir de posibles futuros, y viceversa.

Ante la inminente demolición de El Cartucho y su mundo sociocultural que preocupaba a los participantes del seminario, Guzmán propuso al grupo crear una cápsula de tiempo centrada en el lugar y sus habitantes. Sin embargo, los participantes consideraron que la cápsula debería dirigirse al presente más que al futuro. La cápsula debería hacer aparecer, por así decir, la no-ciudad en la ciudad, poner a los bogotanos en interacción con su negado alter ego cartuchiano. El viaje en el tiempo de la cápsula, por lo tanto, podría considerarse como el tiempo requerido para ir de El Cartucho a otras partes de la ciudad, llevando sus huellas de un lugar a otro. La cápsula comenzó a tomar la forma de un objeto en movimiento. ¿Cómo acercarse a los habitantes de cartucho? ¿Cómo involucrarlos en la construcción de la cápsula? ¿Era verídica su reputación de peligrosos, hostiles, dementes y adictos?

Los participantes en el seminario se apoyaron en un centro de salud que operaba dentro de El Cartucho. Le propusieron al centro de salud una actividad de corte de pelo, afeitado de barba, manicura y maquillaje para los habitantes de calle del lugar, como práctica de conocimiento, de cuidado-salud y artística. Contrataron a un profesor con quien aprendieron los principios del corte de cabello. Compraron maquinillas eléctricas, tijeras, maquillaje, espejos. Eligieron imágenes de peinados y estilos de maquillaje para que los habitantes de El Cartucho tuvieran los materiales para imaginar y comunicar este proceso a sus "peluqueros".

La actividad del seminario dentro del centro de salud duró seis meses. Además de escuchar las historias de los habitantes de la zona y tratar de comprender cómo 
se imaginaban a sí mismos y cómo imaginaban la realidad, se llevó a cabo una documentación histórico-social sobre el vecindario.

El seminario de Guzmán concluyó después de esta primera etapa de acercamiento con El Cartucho, pero de ahí nació el Colectivo Promociona tu Vida Cotidiana [PTVC]. Este grupo continuó con el proyecto de arte crítico basado en el Cartucho y decidió tomar la idea de la cápsula de tiempo como un objeto en movimiento: cápsula de espacio, entonces, que recorrería la ciudad intentando recoser un presente entre esta y su "negatividad". Se concluyó que no había un objeto mejor para contener una colección nómada vinculada al Cartucho que uno de los carros de madera que sus habitantes solían empujar a través de Bogotá para reciclar todo tipo de deshechos. Quedaba por definir su contenido. Además del trabajo realizado en el centro de salud, del que se tenían registros fotográficos y de sonido y la documentación histórico-social, ¿qué otros objetos tendría que contener el carrito? ¿Las pipas para fumar basuco? ¿Los cuchillos "artesanalmente" fabricados por los indigentes para defenderse o robar? ¿La ropa usada? ¿Cómo obtener estos objetos? ¿Y por qué esos en lugar de otros? ¿Acaso estos objetos no implican una clasificación de los habitantes de Cartucho como ladrones, drogadictos y mendigos? ¿En última instancia, no estaba esta clasificación, más cercana a la representación hegemónica que se quería criticar, que a una acción crítica? ¿Cómo evitar que la colección se convirtiese en una representación fija, cómplice de la representación hegemónica en la que se basa la denegación de la corporeidad de la gente de El Cartucho y su expulsión de la comunidad de la vida?

PTVC propuso experimentar la dinámica del trueque buscando una respuesta a estos problemas. No habría una colección fija: cada vez, los artículos de la colección se intercambiarían por otros, mientras se buscaba mantener una conexión con el Cartucho. Un posible algoritmo para este proceso es el siguiente: el carro ingresa en el Cartucho que lleva en su interior los objetos para intercambiar con los habitantes del lugar y, por lo tanto, genera procesos dialógicos de construcción de valor (¿Por qué este objeto a cambio de este otro? ¿Qué representa el objeto en tu vida? ¿Cómo se relaciona con ella?) Luego de haber realizado el intercambio en el Cartucho, el carro se traslada a otro lugar de Bogotá donde presenta los objetos recolectados y los intercambia de nuevo (siempre acompañando el intercambio de un proceso dialógico de construcción del valor). Finalmente, el carro regresa al Cartucho y comienza nuevamente el proceso.

\section{Así nació el Museo de la Calle}

El Museo de la Calle era, por lo tanto, un museo sin categorías fijas cuya colección cambiaba constantemente y sus clasificaciones eran impredecibles. A través de este museo, el colectivo buscaba no solo intercambiar objetos, sino también historias e imaginaciones. El Museo de la Calle buscó, en este sentido, "proteger" el patrimonio cultural, no manteniéndolo sino poniéndolo en movimiento: ¿qué mejor manera de preservar los objetos y visiones de la vida de los habitantes de Cartucho que poniéndolos en manos de los habitantes de la ciudad y permitiéndoles reflexionar sobre la relación entre estos objetos y esas visiones y transformar, a partir de esto, sus propios imaginarios? Con el Museo de la Calle, PTVC buscó construir una comunidad transversal a los espacios ciudad/no ciudad ayudando a crear un flujo de información que, a partir del Cartucho, crease interés por la vida de sus habitantes y por sus historias, tan profundamente vinculadas a los hechos trascendentales de la historia bogotana, colombiana y mundial.

En este caso, se podría decir que la comunicación menor, además de articularse con una minoría (los habitantes de El Cartucho), construye un circuito comunicativo menor (el carrito/museo cambiante que viaja por la ciudad).

\section{¿y hoy?}

La llegada de Internet y de las redes sociales nos obliga a repensar las estrategias de comunicación menor que observamos antes.

El parasitaje que Meireles proponía, y que, como vimos, se basaba en la idea de que la comunicación hegemónica se fundaba en un control centralizado de la información, no puede tener el mismo sentido: acontecimientos como el escándalo alrededor de Cambridge Analytica (ver nota 3) muestran que el "control" de la información para re-esculpir, gestionar o radicalizar las subjetividades, es incluso más eficaz hoy cuando la "inserción" de la información parecería haberse "democratizado" con 
las redes sociales (cualquiera puede ser emisor, pero no por eso disminuye el control) ${ }^{12}$.

Por otro lado, una estrategia como la desarrollada en el "Happening que no tuvo lugar", que detona los presupuestos que garantizan el funcionamiento de la comunicación, tendría que tener en cuenta que la comunicación no parece funcionar sobre las mismas bases en los medios masivos anteriores a las redes sociales que en estas últimas.

Según Nuria Fernández-García “Un reciente estudio de la IMT School for Advanced Studies en Italia señala que las redes sociales ayudan a que las teorías conspirativas persistan y crezcan en el espacio virtual, al crear un ecosistema en el que la verdad de la información deja de importar. Lo que importa es si la información se adapta a una cierta narrativa." (Fernández-García, 2017, p. 70) Ya no importa entonces la referencia a un "afuera", a la realidad, (que es el fundamento detonado por el "Happening que no tuvo lugar") y la comunicación coincidiría más crudamente con el modo en que Deleuze la conceptualizaba. Esta erosión del referente de la información se da, al parecer, debido a diversos filtros y algoritmos que aplican las redes sociales: el filtro burbuja, por ejemplo, "obstaculiza el acceso a la información que podría desafiar o ampliar nuestra visión del mundo (...) A los filtros burbuja se unen las cámaras de resonancia (echo chambers), en las que la información, las ideas o creencias son amplificadas por transmisión y repetición en un sistema cerrado donde las visiones diferentes o alternativas se descartan o se representan de forma minoritaria. Así, los ciudadanos terminan consumiendo noticias ajustadas a su modo de pensar." (Fernández-García, 2017, p. 68) Pero en la base de estos filtros y algoritmos está la construcción de perfiles: Facebook por ejemplo "reúne cotidianamente grandes cantidades de datos o big data (como se los suele llamar) de sus usuarios: intereses, lugares a donde van, redes de amigos, horarios de conexión, instituciones a las que pertenecen y mucho (pero mucho) más. Con esta información, crea perfiles que le

12 Vale citar al respecto el libro "Protocol" de Peter Galloway que, como lo indica el subtítulo, intenta explicar cómo funciona el control en las redes a pesar de su descentralización. Aunque internet ha sido muchas veces calificado como rizomático (concepto desarrollado por Deleuze y Guattari), según Galloway no lo es sino en apariencia: mientras que el rizoma implicaría que todos los nodos estén conectados entre sí, sin ninguna jerarquía entre ellos, muchas partes de internet son jerárquicas. Por demás para Galloway, el principio de internet es el control, no la libertad, que se ejerce a través de los protocolos técnicos que hacen posibles las conexiones en la red. permiten ubicar las publicidades de una manera selectiva." (Magnani, 2017, P. 48) Se trata entonces de lo que podríamos llamar nuestro "devenir información": en la sociedad de control somos codificados en vectores de información, perfiles que alimentan funciones y algoritmos; el output de estas operaciones retorna hacia los sujetos codificados y va moldeando su subjetividad. En particular, como vimos, los filtros refuerzan visiones cerradas y categóricas del mundo lo que tiende a promover identidades monolíticas.

En el prólogo al libro de Suely Rolnik, “Esferas de la insurrección. Apuntes para descolonizar el inconsciente", Paul Preciado escribe: "para Rolnik, todo proceso revolucionario no es más que la introducción de un hiato, de una diferencia en el proceso de subjetivación". (Rolnik 2019, p. 11) Probablemente la comunicación menor hoy intentará producir este hiato.

\section{Referencias}

Alberro, Alexander. (1999). A Media Art: Conceptualisme in Latin America in the 1960s. En Michael Newman \& Jon Bird, Rewriting Conceptual Art. Londres: Reaktion books.

Brito, Ronaldo \& Macieira de Sousa, Eudoro (1981). Cildo Meireles. Rio de Janeiro: Funarte.

Redacción BBC Mundo. (21 de marzo de 2018). 5 claves para entender el escándalo de Cambridge Analytica que hizo que Facebook perdiera US\$37.000 millones en un día. BBC. Recuperado de https://tinyurl.com/v9pnfuj7

Camnitzer, Luis. (2009). Didáctica de la Liberación. Arte conceptualista latinoamericano. Murcia: CENDEAC.

Deleuze, Gilles. (1995). Post-scriptum sobre las sociedades del control. En Conversaciones. (Traductor Pardo, José Luis). Valencia: Pre-textos.

Deleuze, Gilles. (2012). ¿Qué es el acto de creación? (Traductor Prezioso, Bettina). Fermentario N.6

Deleuze, Gilles \& Guattari, Felix. (1978). Kafka. Por una literatura menor (Traductor Aguilar Mora, Jorge). Mexico: Era. 
Deleuze, Gilles \& Guattari, Felix. (1993). ¿Qué es la filosofía? (Traductor Kauf, Tomas). Barcelona: Anagrama.

Deleuze, Gilles \& Guattari, Felix. (2002). Mil mesetas: capitalismo y esquizofrenia (Traductor Vásquez Pérez, José). Valencia: Pre-textos.

Fernández-García, Nuria. (2017). Fake news: una oportunidad para la alfabetización mediática. Nueva Sociedad No 269.

Freire, Paulo (1973). Extensión o Comunicación, México: Siglo XXI.

Galloway, Alexander. (2004). Protocol: How control exists after decentralization, Cambridge: MIT.

Jacoby, Roberto. (2011). El deseo nace del derrumbe, acciones, conceptos, escritos. Barcelona: La central.

Kaplún, Mario. (1985). El comunicador popular. Quito: CIESPAL-CESAP-RADIO NEDERLAND

Magnani, Esteban. (2017). «Big data» y política: El poder de los algoritmos. Nueva Sociedad № 269, pp. 45-55.

Palomares, Ascensión. (2015) Análisis de modelos de comunicación, profesorado-familia, para gestionar conflictos: Estudio de la comunidad educativa de Albacete. Pedagogía Social. Revista Interuniversitaria, núm. 25, pp. 277-298.

Robledo, Angela \& Rodrìguez, Patricia. (2008). Emergencia del sujeto excluido: aproximación genealógica a la no-ciudad en Bogotá. Bogotá: Editorial Pontificia Universidad Javeriana.

Sauvagnargues, Anne. (2002) Art mineur - Art majeur : Gilles Deleuze. Espaces Temps, 78-79. A quoi œuvre l'art? Esthétique et espace public. pp. 120-132. 